\title{
Defining the Genetic Origins of Three Rheumatoid Synovium-derived IgG Rheumatoid Factors
}

\author{
Michael Deftos, * Tsaiwei Olee, * Dennis A. Carson, ** and Pojen P. Chen *\$\$ \\ Departments of * Medicine and ${ }^{\S}$ Pathology, University of California, San Diego, La Jolla, California 92093-0663; and ${ }^{\ddagger}$ Department of \\ Molecular and Experimental Medicine, The Scripps Research Institute, La Jolla, California 92037
}

\begin{abstract}
A major diagnostic marker in most rheumatoid arthritis (RA) patients is the rheumatoid factor (RF), an autoantibody that binds to the Fc region of IgG. To delineate the Ig genes and the underlying mechanism for RF production in RA patients, we applied a systematic approach to define the genetic origins of three IgG RFs derived from the synovial fluid of two RA patients. The results show that two of three IgG RF have substantial numbers of somatic mutations in their variable $(V)$ regions, ranging from 13 to 23 mutations over a stretch of 291-313 nucleotides, resulting in a frequency of 4.4-7.8\%. However, one IgG RF has only one mutation in each $V$ region. This result indicates that an IgG RF may arise from a germline gene by very few mutations. The mutations occur mainly in the complementarity-determining regions (CDRs), and the mutations in the CDRs often lead to amino acid substitutions. Five of the six corresponding germline $\mathbf{V}$ genes have been found to encode either natural autoantibodies or autoantibodies in other autoimmune disorders; and three of the six $\mathrm{V}$ genes have been found in fetal liver. Taken together with other results, the data show that (a) several potentially pathogenic RFs in RA patients arise from natural autoantibodies, and $(b)$ only a few mutations are required to convert the natural autoantibodies to IgG RFs. (J. Clin. Invest. 1994. 93:2545-2553.) Key words: rheumatoid factors • autoantibodies $\bullet$ Ig V genes $\bullet$ germline origins • somatic mutation
\end{abstract}

\section{Introduction}

Rheumatoid arthritis (RA) is a systemic autoimmune disorder characterized by chronic joint inflammation and destruction (1). About $80 \%$ of patients with this autoimmune disorder have a characteristic marker in their sera, termed rheumatoid factor (RF), ${ }^{1}$ an autoantibody that binds to the Fc region of IgG. Studies of RF suggest that it may contribute to immune complex formation, resulting in complement activation, sustaining inflammation, and tissue damage in the rheumatoid synovium (1).

Address correspondence to Dr. Pojen P. Chen, Department of Medicine, 0663, University of California, San Diego, La Jolla, CA 920930663.

Received for publication 3 November 1993 and in revised form 28 January 1994.

1. Abbreviations used in this paper: $\mathrm{CDR}$, complementarity-determining region; FR, framework regions; $R F$, rheumatoid factor; $V$, variable region.

J. Clin. Invest.

(C) The American Society for Clinical Investigation, Inc.

$0021-9738 / 94 / 06 / 2545 / 09 \$ 2.00$

Volume 93, June 1994, 2545-2553
Since the etiopathogenesis of RA remains unclear, a major effort in RA research has been to determine the Ig variable region (V) gene usage and mutation patterns of RFs, and thus to delineate the induction and sustaining mechanisms for RF production. To date, many monoclonal RFs from patients have been generated and characterized (2-13). The results show that these patient-derived RFs use a large number of $\mathrm{V}$ genes from many different gene families. In addition, by comparing each RF nucleotide sequence to its most homologous sequence, the data suggest that most of these RFs probably derive from an antigen-driven response. However, only a portion of human germline Ig V genes have been identified and characterized (14-17). Moreover, recent studies reveal that many human $\mathrm{V}$ genes are highly polymorphic (18-23). Accordingly, it is important to identify precisely the germline origins of an RF to determine accurately its pattern of somatic mutation.

Previously, we described a systematic approach to define the germline origin of an autoantibody (8). Considering that the upstream flanking and the intron regions of a rearranged Ig $\mathrm{V}$ gene do not encode amino acid residues, they generally have much less somatic mutations than the coding regions. Moreover, among different members of a $\mathrm{V}$ gene family, their upstream flanks and introns are normally more heterogeneous than their coding region counterparts. As such, the sequences in these regions of a rearranged $\mathrm{V}$ gene often provide better clues for identifying the corresponding germline $\mathrm{V}$ gene. Accordingly, to assess somatic mutations in an IgG RF designated $\mathrm{L} 1$, we first used the polymerase chain reaction (PCR) to clone the rearranged $\mathrm{Vh}$ and $\mathrm{V} \lambda$ genes from the genomic DNA of the $\mathrm{L} 1$ hybridoma, and then isolated the corresponding germline $\mathrm{V}$ genes from the donor's DNA (9). The combined results revealed that the $\mathrm{L} 1$ heavy and light chain $\mathrm{V}$ regions had, respectively, 16 and 7 somatic mutations, which resulted in 8 and 4 amino acid changes. Strikingly, all eight mutations in the complementarity-determining regions (CDRs) were replacement changes, while only 6 of 11 mutations in the framework regions (FRs) caused amino acid changes (9). The results were analogous to RFs and other autoantibodies in autoimmune mice $(24,25)$. Taken together with L1's high binding affinity toward the Fc fragment, the data argue that the L1 IgG RF may have been driven by the IgG antigen. To examine further the role of somatic mutation in RF production in patients, we isolated the rearranged $\mathrm{V}$ genes and the corresponding germline $\mathrm{V}$ genes of three other IgG RFs derived from two rheumatoid synovia.

\section{Methods}

DNA isolation from the IgG RF-secreting hybridomas and leukocytes of the corresponding donor $R A$ patients. The generation, immunological characterization, and cDNA sequence analyses of the $\mathrm{C} 1, \mathrm{C} 2$, and D1 IgG RFs have been reported previously $(9,12,26)$. The hybrid- 
omas were derived respectively from synovial cells of the seropositive RA patients JC and AD. Genomic DNA was prepared from hybridomas, and from leukocytes of patients JC and AD by the standard phenol extraction method.

$P C R$ primers. The upstream primer generally corresponded to the most 5'-end region of a cloned cDNA, derived by anchored PCR, where the sequence was identical to the most homologous germline DNA sequence (such as the halclU1s primer in Fig. 1; the "U" and "s" denote, respectively, "Upstream" and "sense strand"). Since the shared sequence most likely would be germline, this assured that a primer was not designed over a somatic point mutation. For the $\mathrm{Cl}$ light chain, which belongs to the new V $\lambda 9$ gene family (12), the upstream la9c1U1s primer corresponds to the 5'-end region of the Humla9c1 cDNA sequence (see Fig. 2).

Different 3 '-end primers were used to amplify each rearranged $\mathrm{V}$ gene and its corresponding germline $\mathrm{V}$ gene. For the rearranged genes, the downstream primers generally derived from the CDR3 region (la9cl, ha3d1), the Jh4 downstream exon/intron border (halcl, Humha4c2), the Jk1 region (ka3d1), or the J $\lambda$ downstream exon/intron border (Humlalc2). The la9c1D1c primer (where " $D$ " and the last "c" denote, respectively, Downstream, and the complementary strand; 5'-aacac-ccaca-cgaag-ttggt-3') corresponds to a 20-bp region that straddles the V-J junction of la9c1. The ha3d1Dlc primer (5'agtcg-ccccc-tctgt-atccg-ct-3') is complementary to a 22 -bp region in the CDR3 of ha3d1. The half10Jh4Dlc primer (5'-ctyac-ctgas-gagacggtga-3') corresponds to a 20-bp region that straddles the downstream exon/intron border of $\mathrm{Jh} 1,4,5$, and 6 genes (27); this primer has two degeneracies, one to accommodate a difference among the four $\mathrm{Jh}$ genes and one to accommodate a silent mutation in the Humhalf10 sequence (8). The Jk1c primer (5'-cgttt-gattt-ccacc-ttggt-3') corresponds to a 20-bp region in the Jk1 region (28). The J $\lambda 2 \mathrm{D} 1 \mathrm{c}$ primer (5'-gagaa-gagac-tcacc-tagga-c- $3^{\prime}$ ) corresponds to a 21 -bp region that straddles the downstream exon/intron border of $\mathrm{J} \lambda 2$ (29).

For the germline genes, the downstream primers were designed generally to be complementary to the conserved recombination signal sequence region of the appropriate heavy or light chain gene family, and included degeneracies wherever necessary. The names and the complementary sequences of these primers are given in Figs. 1-6. In all cases, the upstream primers had Sal I sites at their 5'-ends, while downstream primers had either BamHI, PstI, NotI, or KpnI sites at their 5'-ends.

$P C R$-based cloning of the rearranged $V$ genes and their germline counterparts. To amplify a rearranged $\mathrm{V}$ gene, $1 \mu \mathrm{g}$ of hybridoma DNA was mixed with 50 pmoles each of the appropriate primers in a buffer containing $1.5 \mathrm{mM} \mathrm{MgCl}_{2}, 50 \mathrm{mM} \mathrm{KCl}, 10 \mathrm{mM}$ Tris $\mathrm{HCl}, \mathrm{pH} \mathrm{8.3}$, and $0.001 \%(\mathrm{wt} / \mathrm{vol})$ gelatin. The mixture was amplified for $30 \mathrm{cycles}$, each consisting of $1 \mathrm{~min}$ melting at $94^{\circ} \mathrm{C}, 1 \mathrm{~min}$ annealing at $55^{\circ} \mathrm{C}$, and 1 min elongation at $72^{\circ} \mathrm{C}$ (except for 7 min during the last cycle). In al cases, sequence analyses of the amplified DNA showed that they agreed with the corresponding CDNA sequences in the overlapping regions, demonstrating that the amplified DNA represented the desired rearranged $\mathrm{V}$ genes. For isolating the germline gene counterparts of rearranged $\mathrm{V}$ genes, germline DNA from the leukocytes of patient JC and $\mathrm{AD}$ were used.

During the isolation of the germline counterpart of ha4c2 from JC DNA with the ha4c2U1s and hv4D1c primers, the colonies of amplified DNA were screened with the ha4c2U2s oligomer ( 5 '-gggat-ccagacatgg-ggata- $3^{\prime}$ ). Hybridization was done in $5 \times$ SSC $/ 5 \times$ Denhart's solution $/ 0.5 \% \mathrm{SDS} / 5 \mathrm{mM}$ EDTA at $58^{\circ} \mathrm{C}$. Hybridized membranes were washed twice with $6 \times \mathrm{SSC} / 0.1 \% \mathrm{SDS}$ at $37^{\circ} \mathrm{C}$ and once at $58^{\circ} \mathrm{C}$ for 15 min each. Similarly, for the la9c1 germline counterpart, colonies were screened with a 400-bp fragment of la9cl (from its 5 ' flanking region to a BamHI site in its $\mathrm{CDR} 2$ ) at $65^{\circ} \mathrm{C}$; the hybridized papers were washed three times with $0.1 \times \mathrm{SSC} / 0.1 \%$ SDS at $65^{\circ} \mathrm{C}$.

Plasmid DNA from selected clones was sequenced in both directions. Because of possible base infidelity generated during PCR amplification, each of the presented sequences represents either at least two completely identical sequences from the amplified DNA or a consensus sequence from at least three $99 \%$ homologous sequences. The com- puter programs of the University of Wisconsin Genetics Computer Group were used to assemble, edit, and analyze all sequence data (30).

\section{Results}

Identification and characterization of the germline heavy chain $V$ gene for the Cl IgG RF. The rearranged heavy chain V gene from the $\mathrm{Cl}$ hybridoma was amplified with halc1U1s and half10Jh4Dlc; halc1U1s (underlined in Fig. 1) corresponds to a 20-bp stretch of the halc1 cDNA sequence that is identical to the most homologous Humhv1f10 (8). Sequence analysis of the amplified DNA showed that the intron sequence of halc1 differs by two nucleotides from that of hv1f10 and 21-2 (Fig. 1); the latter two genes differ from each other by only one nucleotide (at the nucleotide position -262 , Fig. 1) over a stretch of 614 bases $(8,31)$. The data suggested that halcl may be encoded by either hv1f10, 21-2 or a new Vh1 gene yet to be cloned.

To differentiate among these possibilities, we first used the 21-2U1s primer to reclone the halcl rearranged gene; $21-2 \mathrm{U} 1 \mathrm{~s}$ corresponds to a 5 ' flanking region sequence located upstream of the single base insertion/deletion difference among 21-2 and hv1f10; the latter was cloned previously by PCR using 21-2U1s as the upstream primer (8). Sequence analysis of the amplified DNA showed that it matched the halcl rearranged gene in the overlapping regions, demonstrating that the amplified DNA represented an extended version of the halcl rearranged gene (Fig. 1). The additional 5' sequence of ha1cl was completely identical to hv1f10, but differed from 21-2 by one missing base. The result ruled out 21-2 as the germline origin of halc1.

Then, germline DNA from the donor patient JC was amplified with halclUls and hvlDlc (Fig. 1). HvlDlc contains two degenerate positions and matched completely to all known functional $\mathrm{Vhl}$ genes in the conserved recombination signal sequence region. When eight clones of the amplified DNA were chosen randomly for sequencing, all were identical to hvlf10 except for few independent point mutations, which apparently represented PCR artifacts. Similar results were also obtained when JC DNA was amplified with 21-2U1s and hv1D1c. Accordingly, hv1f10 is most likely to be the germline origin of halcl, and the difference between halcl and hv1f10 represent somatic mutations (Fig. 1). There are 30 nucleotide differences over a region of $652 \mathrm{bp}$, indicating that halcl is highly mutated. The mutated bases include five in the leader and leader' region, two in the intron region, and 23 in the coding region (including 11 in CDR and 12 in FRs). Among the 23 mutations in the coding region, 18 cause amino acid changes; of the 18 replacement mutations, 10 are in CDRs and 8 in FRs. This gives a ratio of replacement mutations to silent mutations ( $R: S$ ratio) of 10 in the CDRs vs. 2 in the FRs. Of the five mutations in the leader region, two are replacement mutations, giving a $\mathbf{R}: \mathrm{S}$ ratio of 0.7 .

Identification and characterization of the germline light chain $V$ gene for the CIIgG RF. The la9c1 rearranged gene was isolated by amplification with la9c1U1s and la9c1D1c (Fig. 2). Sequence analysis of the amplified DNA showed that la9c1 was 97\% homologous to the Humlv901 germline V $\lambda$ 9 gene (Fig. 2) (32). Lv901 was isolated recently by PCR with a degenerate downstream primer (lvdegDlc) from genomic DNA of the Y79 retinoblastoma cell line, from which several $V \lambda$ genes of different families (including Humlv101, Humlv117, Humlv1041, Humlv1042, Humlv318, Humlv413, and 
hv1f10 GAGGTATGAATAATCTGTCTC. ATGAATATGCAAATAACCTTAGATCTACTGAGGTAATATGGATACATCTGGGCCTGAAAGCATCA -197

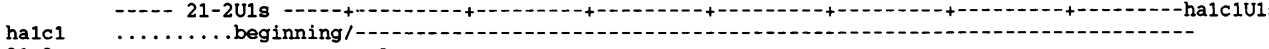

halc1

........beginning/-- be

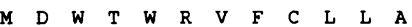

hv1f10

halc

H2 $0 \mathrm{C} 3$

M030

hv1f10

halc

H20C3

M030

hv1f10

halc1

M030

hv $1 \mathrm{f} 10$

ha1c

H20 203

M030

hv1f10

halc1

H20C3

м030

hv1f10

halc1

$\mathrm{H} 2 \mathrm{OC} 3$

M030

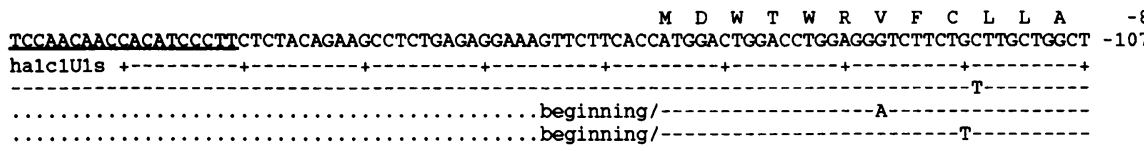

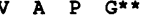

GTAGCTCCAGGTAAAGGGCAACTGGTTCCAGGGCTGAGGAAGGATTTTTTCCAGTTTAGAGGACTGTCATTCTCTACTGTGTCCTCTC

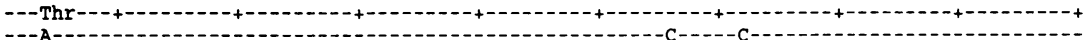

-

$-1 .-1$ intron.

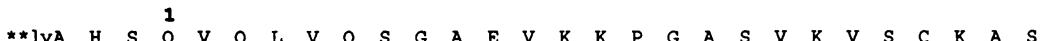

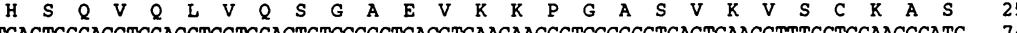
(1) ......-..$\begin{array}{lllllllllllllllllllllllllllllllllll}C & Y & T & F & T & S & Y & Y & Y & M & H & W & V & R & Q & A & P & G & Q & G & L & E & W & M & G & I & I & N & P & S & G\end{array}$ TGGATACACCTTCACCAGCTACTATATGCACTGGGTGCGACAGGCCCCTGGACAAGGGCTTGAGTGGATGGGAATAATCAACCCTAGTGG 164 (1)

$\begin{array}{llllllllllllllllllllllllllllllllll}G & S & T & S & Y & A & Q & K & F & Q & G & R & V & T & M & T & R & D & T & S & T & S & T & V & Y & M & E & L & S & S & 85\end{array}$ TGGTAGCACAAGCTACGCACAGAAGTTCCAGGGCAGAGTCACCATGACCAGGACACGTCCACGAGCACAGTCTACATGGAGCTGAGCAG 254

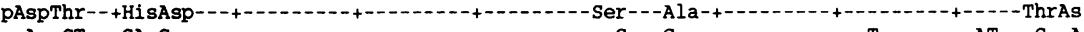
--A--CT---CA-G--1-

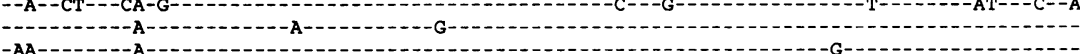

$\begin{array}{lllllllllllllll}\text { L } & R & S & E & D & T & A & V & Y & Y & C & A & R & * 7 \text {-mer* }\end{array}$ CCTGAGATCOGAGGACACGGCCGTGTATTACTGTGCGAGAGACACAGTGTGARAAMCCACAT 316

n-.-Phe-

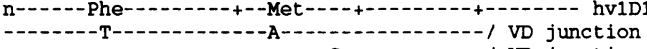

(1)
Figure 1. The germline origin of the $\mathrm{C} 1$ heavy chain, Humhv1f10 (abbreviated hvlf10). Also included are the sequences of the halcl rearranged $\mathrm{Vh}$ gene, the highly homologous 21-2 germline Vhl gene, the $\mathrm{H} 20 \mathrm{C} 3$ anti-ganglioside, and the M030 anti-HIV Vh cDNAs $(8,31,48$, $60)$. The complete nucleotide and amino acid sequences of hv 1 f 10 are given; all other sequences are given only at the positions where they differ from hvlf10 in the overlapping regions. The replacement amino acid residues of half 10 are given; the bars denote identities, while the dots denote the unknown regions and the introns. The regions of three oligomers are underlined and their names are given; the " $R$ " and " $M$ " in the hv1Dlc primer denote $A$ and $G$, and $A$ and $C$, respectively. The CDRs, and the splice and the recombination signal sequences are marked. The sequence data for halcl are available from EMBL/GenBank/ DDBJ under accession number U03892.
Humlv418) had been isolated previously (32-35). Lv901 contains the correct GT donor and AG acceptor signal sequences for RNA splicing, and the consensus heptamer recombination signal sequence. However, it has a stop codon (TAA) at the very end of the $\mathrm{V}$ gene coding region (corresponding to amino acid position 105 in the 3rd CDR), 2 nucleotides before the canonical heptamer sequence (Fig. 2). Therefore, lv901 is a pseudogene. Of note, lv901 is identical to the recently reported DPL22, which contained only the coding and the conserved heptamer region (17).
MCTGAAGAACCCAGCATTECAGCAGCTCCACCATGGCCTGGGCTCCTCTGCTCCTCACCCTCCTCAGTCTCCTCACAGGTCAGGGTGGGC
A 136

lv901

$109 c 1$

$\operatorname{lv} 901$

la9c1

DPL22

$\operatorname{lv} 901$

la9c1

DPL22

$\operatorname{lv} 901$

lagc1

DPL22

$\operatorname{lv} 901$

$109 \mathrm{cl}$

$\mathrm{J} \lambda 2$

DPL22

Iv901

la9c1

J $\mathrm{N2} 2$

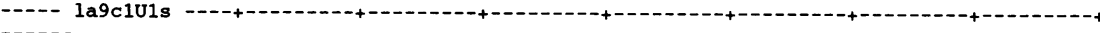

AGTGGGCTGGGCCCAAAGGGACCCCACCTCCCAGCCTCCATCTCCCCATCCCTGCTCTTCCTCCTCCAACAGCTCATCAGCCACCCAC -

$\star \star 1 y S-1,2$ 1

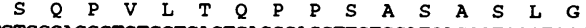
CAACAGGACCCATGGTTTCTGTGTTTCCAGGGTCCCTCTCCCAGCCTGTGCTGACTCAGCCACCTTCTGCATCAGCCTCCCTGGGA

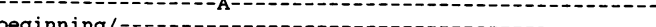
beginning/

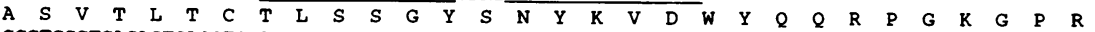
GCCTCGGTCACACTCACCTGCACCCTGAGCAGCGGCTACAGTAATTATAAAGTGGACTGGTACCAGCAGAGACCAGGGAAGGGCCCCGG 135 -

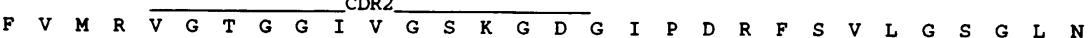
-

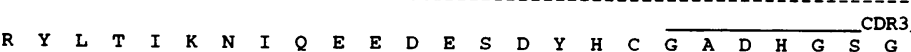

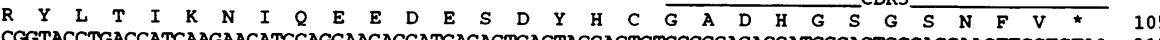
CGGTACCTGACCATCAAGAACATCCAGGAAGAGGATGAGAGTGACTACCACTGTGGGGCAGACCATGGCAGTGGGAGCAACTTCGTGTAA 315

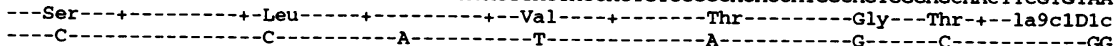

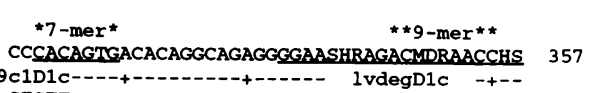

CCCACAGTCACACAGGCAGAGGGAASHRAGACMDRAACCHS 357

GRCITI

GTATT
Figure 2. The germline origin of the $\mathrm{Cl} \mathrm{L}$ chain, Humlv901 (abbreviated $l v 901)$. Also included is the la9cl rearranged gene and the recently reported DPL22 germline gene (17). The complete nucleotide and amino acid sequences of lv901 are given, while the la9c1 and DPL22 sequences are given only at the positions where they differ from lv901 in the overlapping regions. The replacement amino acid residues of la9cl are given; the bars denote identities. The regions of three oligomers are underlined and their names are given. The $S, H, R, M$, and $D$ in the lvdegDlc primer denote the degenerate positions; they represent respectively $C G, A C T, A G$, $A C$, and AGT. The CDRs, and the splice and the recombination signal sequences are marked. The sequence data for la9cl are available under accession number U03899. 
Considering that lv901 is a pseudogene, it was possible that la9cl might be encoded by a functional $\mathrm{V} \lambda 9$ gene yet to be identified. Accordingly, JC DNA was amplified with la9c1U1s and lvdegD1c, and the clones of amplified DNA were screened with la9c1. When seven positive clones were chosen randomly for sequencing, all were found to be almost identical to lv901, except for few independent single base differences that likely represent PCR artifacts. It should be noted that lv901 is completely identical to la9 1 in the $5^{\prime}$ flanking, leader, intron and leader' regions. Together, these results suggest strongly that lv901 is most likely the germline counterpart of la9cl. As can be seen in Fig. 2, la9cl differs from lv901 by 14 nucleotides over a region of $518 \mathrm{bp}$. Of the 14 differences, eight are in FRs and six in CDRs; they cause four amino acid changes in FRs and four in CDRs, resulting in a R:S ratio of one in the FRs and two in the CDRs.

Identification and characterization of the germline heavy chain $V$ gene for the $C 2 \operatorname{IgG} R F$. The $\mathrm{C} 2$ rearranged heavy chain gene was amplified with ha4c2U1s and half10Jh4D1c; ha4c2U1s corresponds to the most $5^{\prime}$ region of ha $4 \mathrm{c} 2$ that was shared by $71-4$ (36). Sequence analysis showed that the intron of ha4c2 was completely identical to that of 71-4, while the $\mathrm{V}$ gene coding region of ha4c2 is one nucleotide more similar to 4.11 than $71-4$ (Fig. 3 ). The reported 4.11 sequence contains only the coding region (37).
Considering the substantial differences by which ha4c2 differs from 71-4 and 4.11 (particularly in the second CDR), it was possible that ha4c 2 might be encoded by an unknown Vh4 germline gene that differs significantly from 71-4 and 4.11. Accordingly, we amplified JC DNA with ha4c2U1s and hv4D1c; the latter was complementary to a region shared by all reported Vh4 germline genes $(31,38,39)$. Initial sequence analysis of 15 resultant clones showed that the amplified DNA contained several different Vh4 germline genes (data not shown). Therefore, plasmid colonies from amplified DNA were screened with ha4c $2 \mathrm{U} 2 \mathrm{~s}$, corresponding to an intron region of ha4c2 that is identical to that of 71-4, but different from most other Vh4 germline genes. Eight positive clones were chosen randomly for sequencing; six were found to be almost identical to each other (except for few single base differences) and thus represented a single Vh4 gene, designated Humhv4c2 (Fig. 3). $\mathrm{Hv} 4 \mathrm{c} 2$ is identical to 4.11 in the coding region, and differs from 71-4 by one single base, resulting an amino acid change from Ile in $\mathrm{hv} 4 \mathrm{c} 2$ to $\mathrm{Val}$ in $71-4$ at amino acid position $29(31,37)$. Importantly, none of the clones were found to have an extended CDR2 similar to the CDR2 of ha4c2. Taken together, these data show that hv4c2 is almost certainly the germline counterpart of ha $4 \mathrm{c} 2$, and thus provide further support for the proposed segmental duplication of a portion of CDR2 in ha4c2 (Fig. 3). In addition to this 18-bp duplication, ha4c2 differs

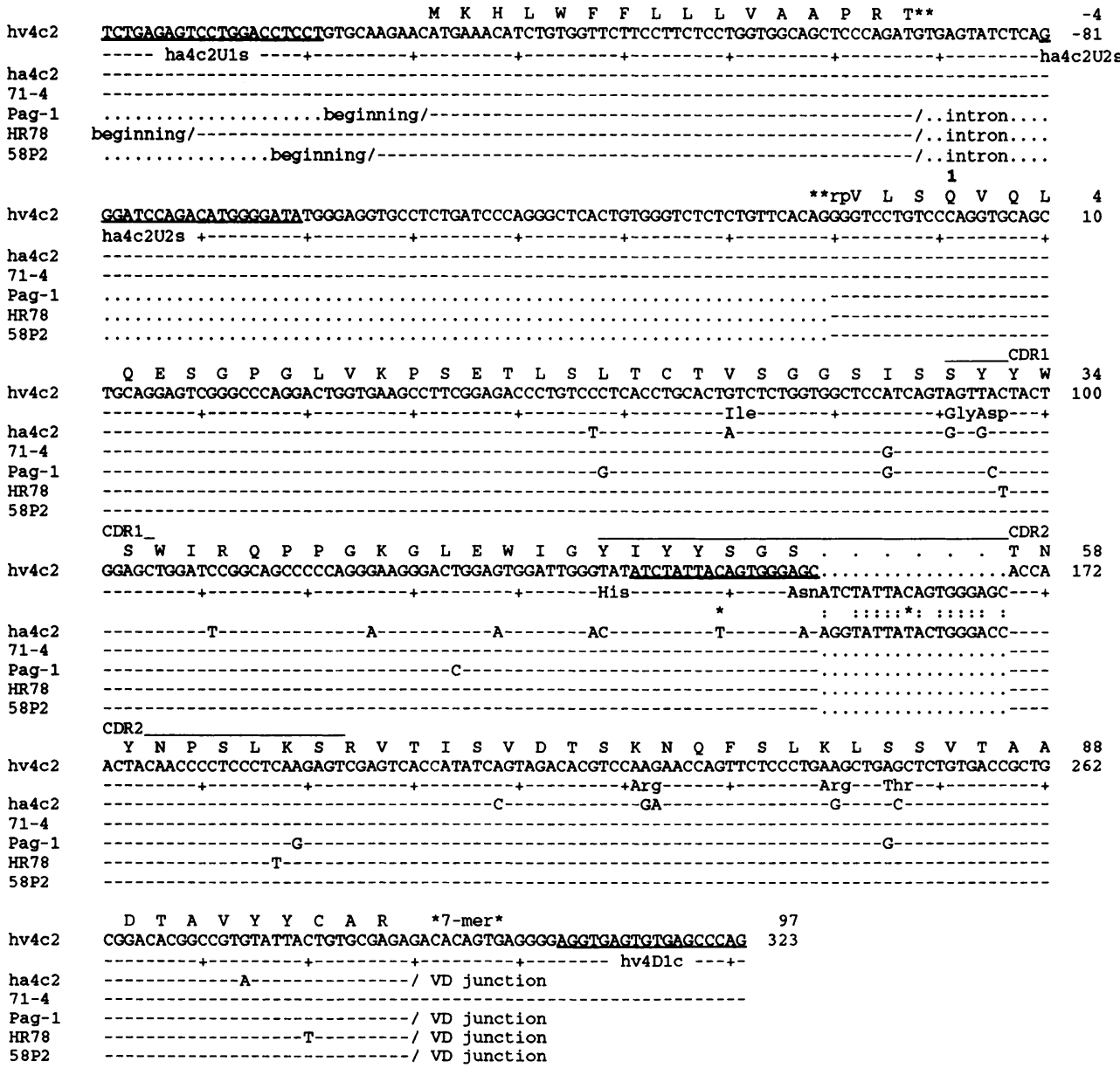

Figure 3. The germline origin of the $\mathrm{C} 2$ heavy chain, Humhv4c2 (abbreviated $h v 4 c 2$ ). Also included are the sequences of the ha4c2 rearranged $V h$ gene, the highly homologous 71-4 germline Vh4 gene, the Pag-1 anti-Rh, the HR78 anti-lipid $A$, and the 58P2 Vh cDNAs $(36,46,49$, 61 ). The complete nucleotide and amino acid sequences of hv $4 \mathrm{c} 2$ are given; the CDR2 region of hv4c2 that is proposed to be duplicated is underlined, and the duplicated 18 bases are given beneath the suggested insertion site (denoted by dots). All other sequences are given only at positions where they differ from $h v 4 c 2$ in the overlapping regions. The bars denote identities, while the dots denote the unknown regions, and the introns. The replacement amino acid residues of ha4c2 are given; and the identities between the inserted 18 bases in ha4c 2 and the duplicated segment in hv4c2 are marked by colons. The regions of three oligomers are underlined and their names are given. The CDRs, the splice and the recombination signal sequences are marked. The sequence data for ha $4 \mathrm{c} 2$ and hv4c2 are available under accession numbers U03895 and U03896, respectively. 
from hv4c2 by another $17 \mathrm{bp}$, including 12 in FRs and five in CDRs. These deviated nucleotides in ha4c 2 cause four amino acid changes in FRs and four in CDRs, resulting in a R:S ratio of 0.5 for the FRs and four for the CDRs.

Identification and characterization of the germline light chain $V$ gene for the $C 2 \operatorname{Ig} G R F$. The $\mathrm{C} 2$ rearranged light chain gene was amplified with la1c2U1s and J $\lambda 2 \mathrm{D} 1 \mathrm{c}$; lalc2U1s corresponds to a lalc2 sequence that is identical to $\operatorname{lv} 1 \mathrm{~L} 1$ (9). Subsequently, la 1c2U1s was paired with Iv1 17D1c to clone the corresponding germline gene; lv117Dlc was complementary to a region shared by many $V \lambda 1$ germline genes $(9,34)$. Seven clones from the amplified DNA were sequenced; three were found to be identical to each other, but differed from all known human $\mathrm{V} \lambda 1$ germline genes, and thus represented a new germline $\mathrm{V} \lambda 1$ gene. This gene is $97 \%$ homologous to la1c2 over a region of 481 bases, and differs from la $1 \mathrm{c} 2$ by only two nucleotides over a stretch of $188 \mathrm{bp}$ in the $5^{\prime}$ flanking, leader, intron and leader' regions. Combined, these data suggest that this $\mathrm{V} \lambda 1$ germline is the germline counterpart of lalc2; thus, the new gene was designated Humlv1c2. Of the remaining four clones, two were identical to each other, and to lv1c2 in the coding region, but differed from $1 v 1 \mathrm{c} 2$ by one single base in the intron (Fig. 4). These two sequences apparently represent another new $\mathrm{V} \lambda 1$ germline gene closely related to $1 \mathrm{v} 1 \mathrm{c} 2$; the new gene was designated Humlv1c2c. The last two clones were identical to each other, and differed from the lv1Ll gene by one single base (changing from $G$ in $1 v 1 \mathrm{Ll}$ to $A$ at $13 \mathrm{bp}$ downstream of the heptamer recombination signal sequence region), and thus represent an additional new $\mathrm{V} \lambda 1$ germline gene, designated Humlv1Lla (Fig. 4). Of note, lv1c2 and lv1c2c are identical to the recently reported DPL1 in the coding region (17); the reported DPL1 gene contained only the coding region sequence.
In addition to the two different bases between la1c2 and $1 v 1 c 2$ noted earlier, la $1 \mathrm{c} 2$ differs from lv $1 \mathrm{c} 2$ by 13 bases in the coding regions; these deviations most likely represent somatic mutations. There are nine mutations in the FRs, of which three are replacement changes, and four mutations in the CDRs, of which three are replacement changes. This gives a R:S ratio of 0.5 for the FRs and 3.0 for the CDRs.

Identification and characterization of the germline heavy chain V gene for the DI IgG RF. Previously, we reported that the coding region of the ha3d 1 cDNA sequence was most homologous to VH26 (9). Subsequently, the ha3d1 cDNA sequence was extended to $\sim 80$ bases upstream of the leader region by sequencing additional ha3d 1 clones. Surprisingly, the $5^{\prime}$ flanking region of ha3d1 was more similar to hv3005 and $12-2$ than to the VH26 gene $(31,40)$. Accordingly, an upstream primer (ha3d1U1s) corresponding to a conserved region between ha3d 1 and hv3005 was prepared and was paired with ha3d1D1c to amplify the ha3d1 rearranged gene. Subsequently, when we were ready to clone the ha3d 1 germline gene, we noted that the ha3d1 cDNA sequence was most homologous to the newly reported N80P1M cDNA sequence (41). Accordingly, we prepared a primer (ha3d1U2s) that corresponds to an identical region shared by ha3dl and N80P1M, and is located further upstream of ha3d1U1s. Germline DNA from patient $A D$ was amplified with ha3d1U2s and hv3D1c; the latter primer contained two degenerate positions and matched completely to all known functional human $\mathrm{Vh} 3$ germline genes in the conserved recombination signal sequence region $(31,40)$ (Fig. 5). Seven clones from the amplified DNA were chosen randomly for sequence analysis; three clones were found to be almost identical to each other (except for few single base differences probably due to PCR artifacts)

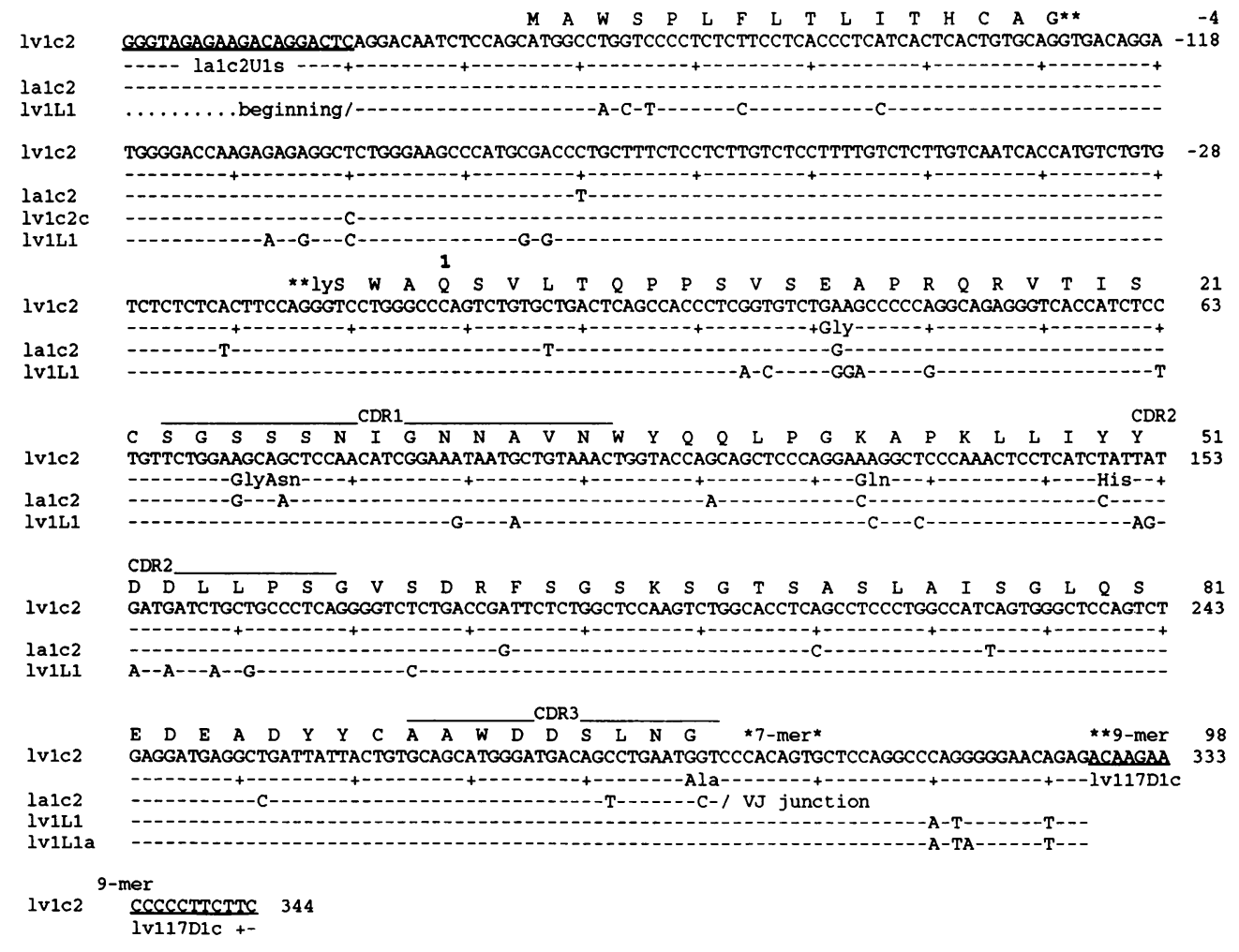

Figure 4. The germline origin of the $\mathrm{C} 2 \mathrm{~L}$ chain, Humlv lc2 (abbreviated $l v 1 c 2$ ). Also included are the la1c2 rearranged gene, Humlv1L1, as well as Humlv1Lla and Humlv1c2c germline genes isolated in the current study. The complete nucleotide and amino acid sequences of $1 v 1 \mathrm{c} 2$ are given, while the lalc2 and the lv1L1 sequences are given only at positions where they differ from lv1c2 in the overlapping regions; lv1c2c and lv1Lla are given only for the segments where they differ from lv1c2 and lv1L1, respectively. The bars denote the identities. The replacement amino acid residues of la $1 \mathrm{c} 2$ are given, and the regions of two oligomers are underlined and their names are given. The CDRs, and the splice and the recombination signal sequences are marked. The sequence data for la $1 \mathrm{c} 2, \operatorname{lv} 1 \mathrm{c} 2$, $1 \mathrm{v} 1 \mathrm{c} 2 \mathrm{c}$, and lv1Lla are available under accession numbers U03898, U03900, U03901, and U03902, 
$\begin{array}{llllllllllll}M & E & L & G & L & C & W & V & F & \text { L } & \text { V } & -9\end{array}$

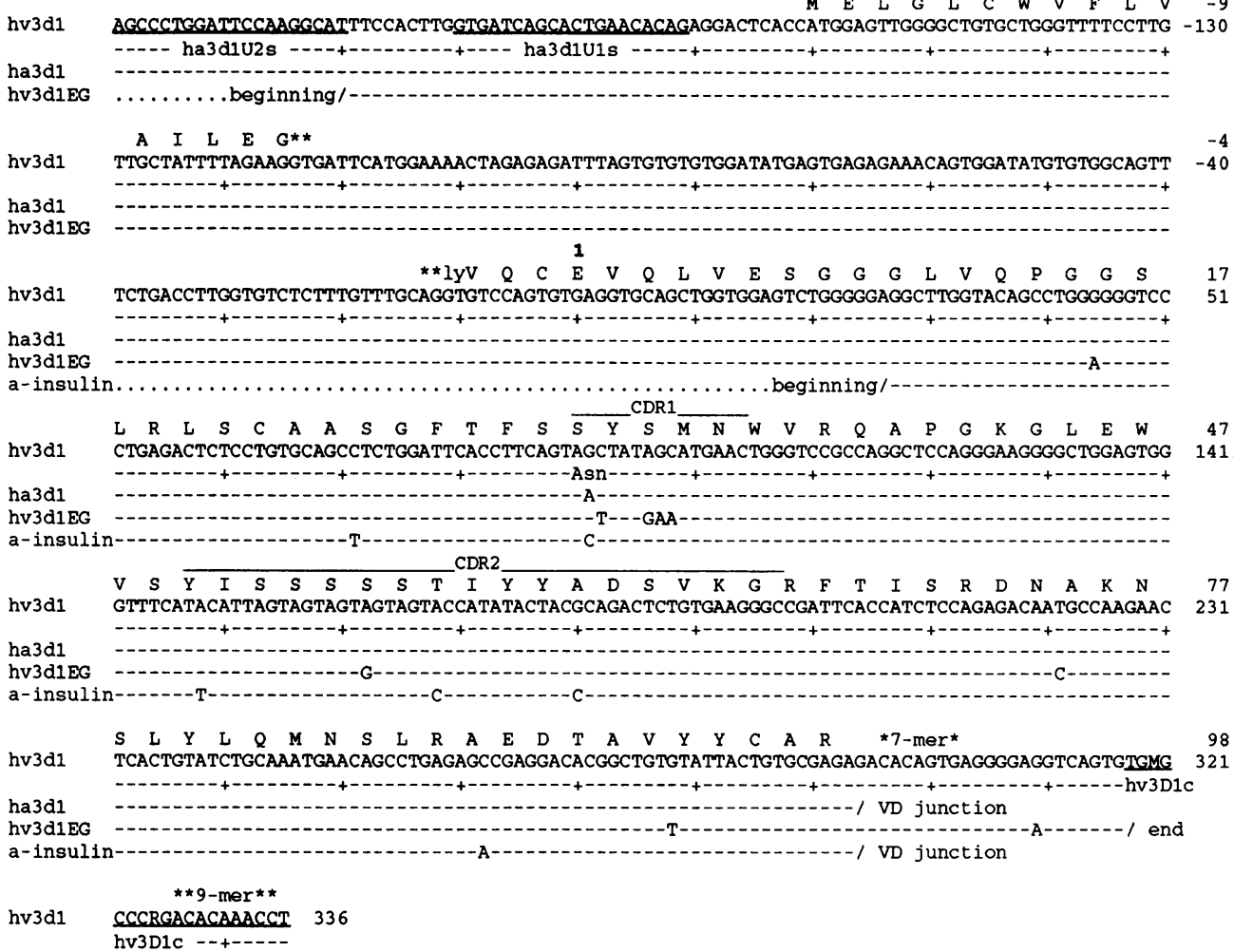

Figure 5. The germline origin of the D1 heavy chain, Humhv3d1 (abbreviated $h v 3 d l$ ). Also included are the sequences of the ha3dl rearranged $\mathrm{Vh}$ gene, the highly homologous Humhv3d1EG gene isolated in the current study, and the No. 19 anti-insulin Vh cDNAs (50). The complete nucleotide and amino acid sequences of hv3dl are given; all other sequences are given only at the positions where they differ from hv3d1 in the overlapping regions. The replacement amino acid residues of ha3d 1 are given; the bars denote the identities, while the dots denote the unknown regions. The regions of three oligomers are underlined and their names are given; the $M$ and $R$ in the hv3Dlc primer denote $A$ and $C$, and $A$ and $G$, respectively. The CDRs, and the splice and the recombination signal sequences are marked. The sequence data for ha3d 1 and hv3d1EG are available under accession numbers U03894 and U03893, respectively. and thus represented a Vh3 gene, designated Humhv3d1. Hv3d1 differs from ha3d1 by only one single base in CDR1, resulting in an amino acid change from Ser in hv3dl to Asn in ha3d 1 at amino acid position 31 . Of the remaining four clones, three were $>99 \%$ homologous to each other, and thus represented another $\mathrm{Vh} 3$ gene. The consensus sequence of these three clones differs from hv3dl by nine nucleotides and two amino acid residues, changing from two Ser at positions 33 and 55 in hv3d 1 to Glu and Gly, respectively; accordingly, the new Vh3 gene was designated Humhv3d1EG. Of note, hv3d1 is identical to the recently reported WHG26 (from nucleotide positions -197 to 294 in Fig. 5) and V3-48 (16, 42); and hv3d1EG is identical to DP58 (15); the reported DP58 contains only the coding region.

Identification and characterization of the germline light chain $V$ genes for the DI IgG RF. The Humka3d1 cDNA is identical to the $\mathrm{Vg} / \mathrm{L} 6 \mathrm{p}$ germline gene except for one single base difference at the $\mathrm{V}-\mathrm{J}$ junction, suggesting that $\mathrm{Vg}$ is the germline counterpart of ka3dl $(43,44)$. To verify this contention, we used the VgU1s and Jk1D1c primers to amplify the ka3d1 rearranged gene; VgU1s corresponds to a 5' flanking region of $\mathrm{Vg}$. Analysis of the amplified DNA showed that the cloned gene agreed with the ka3d 1 cDNA sequence, indicating that the cloned DNA is the ka3d1 rearranged gene. The rearranged gene contains an intron completely identical to that of $\mathrm{Vg}$.

To rule out the possibility that the single base deviation in ka3dl represents an allelic difference, we prepared the new VgU2s primer corresponding to a sequence within the cloned ka3d 1 rearranged gene, and paired it with $\mathrm{VgDlc}$ to amplify germline DNA from patient AD (Fig. 6); VgDic corresponds to a 3' flanking region of $\mathrm{Vg}$. Sequence analysis of the amplified
DNA revealed two clones identical to $\mathrm{Vg}$. These results establish that $\mathrm{Vg}$ is the germline origin of ka3d 1 , and suggest that the single base difference at the VJ junction represents either an imprecise joining or, less likely, a somatic mutation.

\section{Discussion}

Using a systematic approach, we defined the most likely germline origins of three IgG RFs. The results, in turn, allow for an accurate assessment of the somatic mutations in these three IgG RFs, as summarized in Table I. The data of L1 IgG RF are included for comparison. Within the coding regions, three of four IgG RFs have substantial numbers of mutations, ranging from four in the $\mathrm{L} 1$ light chain to 23 in the $\mathrm{Cl}$ heavy chain, resulting in a mutation frequency of $1.4-7.8 \%$. In contrast, the heavy and light chains of D1 have only one mutation each, resulting in a mutation frequency of only $0.3 \%$. The low mutation frequency in D1 IgG RF is analogous to the high affinity anti-DNA IgG antibodies in Balb/c mice reported previously (45). Together, these data show that, although several potentially pathogenic IgG RFs contain a significant number of somatic mutations, certain IgG RFs in RA patients may be encoded directly by germline genes with very few mutations.

Compared with the high mutation frequency in the coding regions of the analyzed IgG RFs, somatic mutations in the $5^{\prime}$ flanking, leader, and intron regions of these IgG RFs is much rarer. No mutation was observed in all eight 5 ' flanking regions. Similarly, six of eight intron regions did not have any mutations, while there were two mutations each in the $\mathrm{C} 1$ heavy chain and the $\mathrm{C} 2$ light chain. For the leader and leader' regions, seven of eight rearranged $\mathrm{V}$ genes did not contain any mutations, while the $\mathrm{Cl}$ heavy chain contained five mutations. 


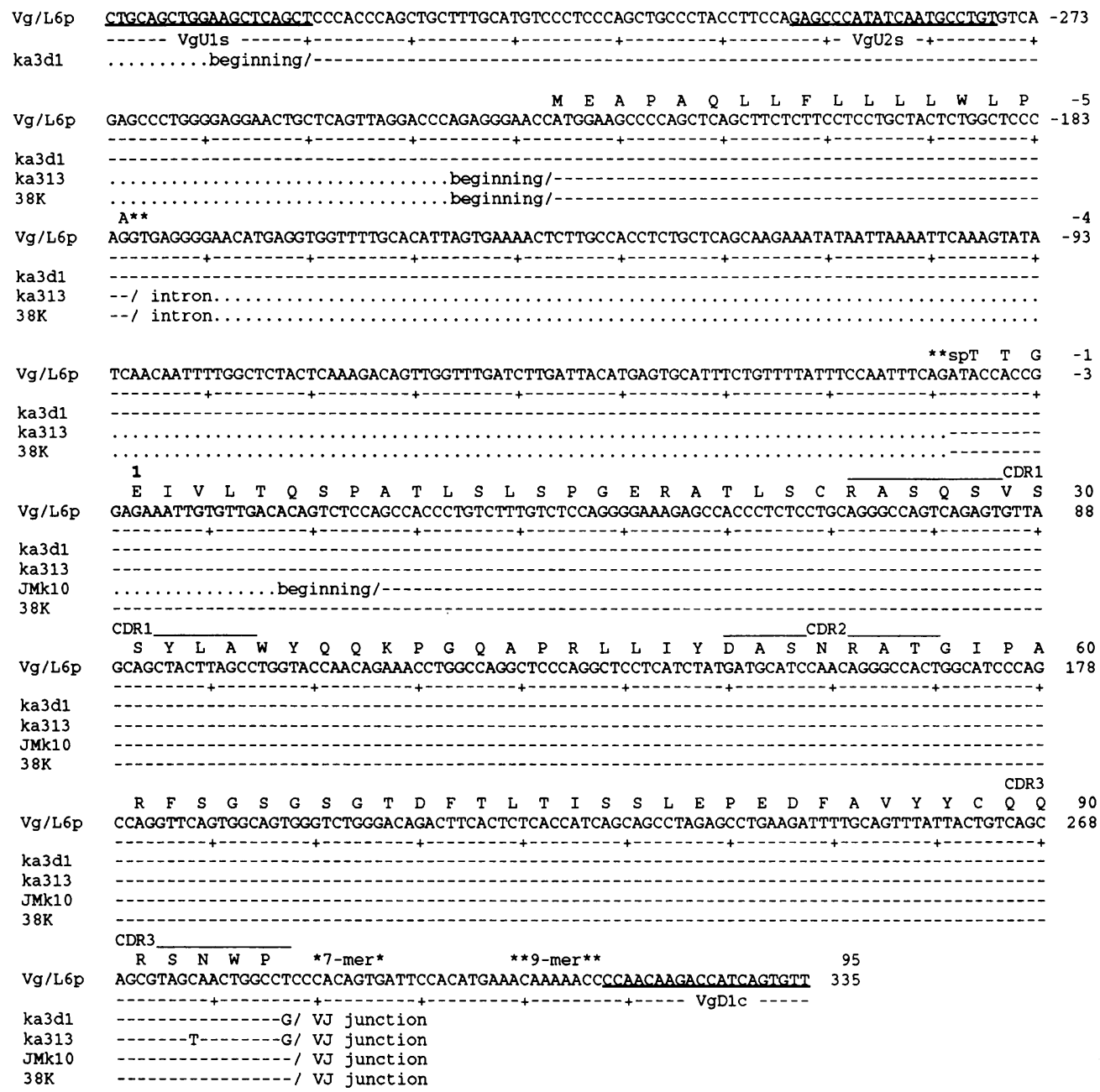

Figure 6. The germline origin of the D1 L chain, $\mathrm{Vg} / \mathrm{L6}(43,44)$. Also included are the ka3d 1 rearranged gene, the kim13.1 anti-cardiolipin (Humka313), the JMk10 anti-hepatitis $B$, and $38 \mathrm{~K}(51,52,62)$. The complete nucleotide and amino acid sequences of $\mathrm{Vg}$ are given, while other sequences are given only at the positions where they differ from $\mathrm{Vg}$ in the overlapping regions; the bars denote the identities. The regions of three oligomers are underlined and their names are given. The CDRs, and the splice and the recombination signal sequences are marked. The sequence data for ka3d 1 are available under accession number U03897.
Overall, by including the 5 ' flanking, leader and intron regions in the comparison of a rearranged $\mathrm{V}$ gene and its germline counterpart, the similarity is increased substantially. For example, the similarity between halcl and hv1f10 increases from $92 \%$ in their coding regions to $95 \%$ for the entire regions. While assignment of hvlf10 as the germline gene for halcl based on the $92 \%$ similarity in the coding region may be too speculative, a more extensive comparison of halcl and hvlf10 over a stretch of 632 bases assures that the hv1f10 assignment is likely to be correct. Therefore, the data from four synovium-derived IgG RFs demonstrate clearly the necessity to clone the rearranged genes of IgG autoantibodies in order to define their germline origins.

Table I also compares mutations in the CDRs and the FRs of each expressed $\mathrm{V}$ gene. Note that the mutation frequency is always higher in CDRs than in FRs for each V gene; and the $\mathrm{R} / \mathrm{S}$ ratio is always $<2.9$ in FRs, but $>2.9$ in CDRs, except for the $\mathrm{C} 1$ light chain. Together, these data support the contention that IgG RF production in the inflamed joints of RA patients is driven and sustained by antigen, and not by polyclonal $B$ cell mitogens.

Previously, the hv1L1 gene for the L1 IgG RF was noted to be identical to the 20P3 cDNA found in fetal liver, and to the heavy chain of the ML3 polyspecific IgM RF derived from a fetal spleen $(46,47)$. The data led us to suggest that the $\mathrm{L} 1 \mathrm{IgG}$ RF probably arose from a physiological natural autoantibody that escaped normal mechanisms of regulation (9). According to this hypothesis, one would expect to find that most RA-derived IgG RFs share similar V genes with polyspecific natural autoantibodies and autoantibodies of other binding specificities. In this regard, it is interesting to note that the hv1f10, hv4c2, and V3-48 genes for RFs are $98 \%$ homologous to the heavy chains of H20C3 anti-ganglioside, Pag-1 anti-Rh and No. 19 anti-insulin antibodies, respectively (48-50). Moreover, hv4c2 is identical to 58P2 from a fetal liver, and V3-48 is $99.3 \%$ homologous to N80P1M from a neonate $(41,46)$. For the light chains, lv901 and $\mathrm{Vg}$ are respectively $100 \%$ and $99.7 \%$ homologous to the light chains of $\mathrm{Cal} 4 \mathrm{G}$ anti-erythrocyte and Kim 13.1 natural autoantibodies $(17,51)$. In addition, $\mathrm{Vg}$ is identical to $38 \mathrm{~K}$ from a fetal liver (52). It should be noted that the light chain data are quite preliminary, as only very limited studies of autoantibody light chains and fetal expressed light chains have been reported (52-54). Viewed as a whole, these data suggest that several potentially pathogenic RFs in RA patients arise from natural autoantibodies.

Human D minigenes have been implicated in the generation of CDRs of Vh genes during evolution $(55,56)$. Accordingly, we compared the 18 additional bases in the CDR2 of ha4c 2 with all human Dh genes, and found that a stretch of 11 bases (TATTA-TAGTG-G, positions $154-164$ in Fig. 3 ) is highly homologous to the D2 gene (TATTG-TAGTG-G, positions 5-15), sharing $10 / 11$ nucleotides (57). This finding 


\begin{tabular}{|c|c|c|c|c|c|c|c|}
\hline \multirow[b]{2}{*}{ Names } & \multirow[b]{2}{*}{ 5' Flank } & \multirow[b]{2}{*}{ Leader } & \multirow[b]{2}{*}{ Intron } & \multicolumn{3}{|c|}{ Coding region } & \multirow[b]{2}{*}{ Total } \\
\hline & & & & Entire & CDRs & FRs & \\
\hline \multicolumn{8}{|l|}{ Cl IgG RF } \\
\hline halcl/hv1f10 & $0 / 124,0 \%$ & $5 / 57,8.8 \%$ & $2 / 85,2.3 \%$ & $23 / 294,7.8 \%$ & $11 / 66,16.7 \%$ & $12 / 228,5.3 \%$ & $30 / 632,4.7 \%$ \\
\hline $\mathrm{R} / \mathrm{S}$, ratio: & & $2 / 3,0.7$ & & & $10 / 1,10$ & $8 / 4,2$ & \\
\hline 1 a9c1/1v901 & $0 / 12,0 \%$ & $0 / 57,0 \%$ & $0 / 136,0 \%$ & $14 / 313,4.5 \%$ & $\begin{array}{l}6 / 106,5.7 \% \\
4 / 2,2\end{array}$ & $\begin{array}{l}8 / 207,3.9 \% \\
4 / 4,1\end{array}$ & $14 / 518,2.7 \%$ \\
\hline \multicolumn{8}{|l|}{ C2 IgG RF } \\
\hline ha $4 c 2 / h v 4 c 2$ & $0 / 10,0 \%$ & $0 / 57,0 \%$ & $0 / 82,0 \%$ & $17 / 291,5.8 \%$ & $\begin{array}{l}5 / 63,7.9 \% \\
4 / 1,4\end{array}$ & $\begin{array}{c}12 / 228,5.3 \% \\
4 / 8,0.5\end{array}$ & $17 / 440,3.9 \%$ \\
\hline $1 \mathrm{a} 1 \mathrm{c} 2 / 1 \mathrm{v} 1 \mathrm{c} 2$ & $0 / 15,0 \%$ & $0 / 57,0 \%$ & $2 / 115,1.7 \%$ & $13 / 294,4.4 \%$ & $\begin{array}{l}4 / 87,4.6 \% \\
3 / 1,3\end{array}$ & $\begin{array}{l}9 / 207,4.3 \% \\
3 / 6,0.5\end{array}$ & $15 / 481,3.1 \%$ \\
\hline \multicolumn{8}{|l|}{ D1 IgG RF } \\
\hline $\begin{array}{l}\text { ha3d1/hv3dl } \\
\text { (V3-48) }\end{array}$ & $0 / 39,0 \%$ & $0 / 57,0 \%$ & $0 / 103,0 \%$ & $1 / 294,0.3 \%$ & $\begin{array}{l}1 / 66,1.5 \% \\
1 / 0, \infty\end{array}$ & $0 / 228,0 \%$ & $1 / 493,0.2 \%$ \\
\hline $\mathrm{ka} 3 \mathrm{~d} 1 / \mathrm{Vg}$ & $0 / 113,0 \%$ & $0 / 60,0 \%$ & $0 / 169,0 \%$ & $1 / 285,0.4 \%$ & $\begin{array}{l}1 / 81,1.2 \% \\
0 / 1,0\end{array}$ & $0 / 204,0 \%$ & $1 / 627,0.2 \%$ \\
\hline $\begin{array}{l}\text { L1 IgG RF } \\
\text { halL1/hv1L1 }\end{array}$ & $0 / 37,0 \%$ & $0 / 57,0 \%$ & $0 / 86,0 \%$ & $15 / 294,5.1 \%$ & $\begin{array}{l}6 / 66,9.1 \% \\
6 / 0, \infty\end{array}$ & $\begin{array}{l}9 / 228,3.9 \% \\
5 / 4,1.8\end{array}$ & $15 / 474,3.2 \%$ \\
\hline $1 \mathrm{a} 1 \mathrm{Ll} / 1 \mathrm{v} 1 \mathrm{Ll}$ & $0 / 24,0 \%$ & $0 / 57,0 \%$ & $0 / 115,0 \%$ & $4 / 294,1.4 \%$ & $\begin{array}{l}2 / 87,2.3 \% \\
2 / 0, \infty\end{array}$ & $\begin{array}{l}2 / 207,1 \% \\
1 / 1,1\end{array}$ & $4 / 490,0.8 \%$ \\
\hline
\end{tabular}

raises the possibility that a human $\mathrm{Dh}$ gene may have participated in the somatic diversification of a heavy chain CDR2, in addition to CDR3.

The $\mathrm{V}$ regions of $\mathrm{D} 1$ differ from the corresponding germline $\mathrm{V}$ genes by only one base in the CDR1 of ha3d1, resulting in an amino acid substitution from Ser to Asn (Fig. 5). Previously, characterization of four high affinity IgG anti-DNA antibodies from non-autoimmune prone Balb/c mice revealed that the expressed Vh gene sequences are identical to the corresponding germline genes (45). Moreover, one of the four expressed Vk genes (i.e., R4A.12) is also identical to the $\mathrm{K} 5.1$ germline gene. This finding led the authors to suggest that high affinity autoantibodies may exist in a normal individual, but their expression is usually suppressed. In the future, it may be important to study the contribution of the Ser to Asn change in the D1 IgG RF, and to search for additional high affinity IgG autoantibodies with no somatic mutations, in order to determine the prevalence and significance of the germline gene encoded high affinity IgG autoantibodies in normal and disease states.

Although chicken $\mathrm{V} \lambda$ pseudogenes diversify by gene conversion to generate the functional repertoire $(58,59)$, usage of defective human $\mathrm{V}$ genes has not been observed. In this context, the usage of lv901 by $\mathrm{Cl}$ RF shows that a human $\mathrm{V}$ gene with a stop codon in the coding region may still be expressed. In the future, it may be important to determine whether the expression of the lv901 pseudogene represents a normal event or an abnormality associated with diseases.

\section{Acknowledgments}

The authors gratefully acknowledge the secretarial assistance of Ms. Jane Uhle in the preparation of this manuscript.
This research was supported by grants AI-32243, AR-25443, and AR-40770 from the National Institutes of Health (NIH), and by computer facilities provided under NIH National Center for Research Resources GCRC grant M01 RR-00833.

\section{References}

1. Harris, E. D. Jr. 1990. Rheumatoid arthritis: pathophysiology and implications for therapy. N. Engl. J. Med. 322:1277-1289.

2. Robbins, D. L., T. P. Kenny, M. J. Coloma, J. V. Gavilondo-Cowley, R. W. Soto-Gil, P. P. Chen, and J. W. Larrick. 1990. Serological and molecular characterization of a human monoclonal rheumatoid factor derived from rheumatoid synovial cells. Arthritis Rheum. 33:1188-1195.

3. Pascual, V., I. Randen, K. Thompson, M. Sioud, O. Forre, J. Natvig, and J. D. Capra. 1990. The complete nucleotide sequences of the heavy chain variable regions of six monospecific rheumatoid factors derived from Epstein-Barr virustransformed B cells isolated from the synovial tissue of patients with rheumatoid arthritis. J. Clin. Invest. 86:1320-1328.

4. Victor, K. D., I. Randen, K. Thompson, O. Forre, J. B. Natvig, S. M. Fu, and J. C. Capra. 1991. Rheumatoid factors isolated from patients with autoimmune disorders are derived from germline genes distinct from those encoding the Wa, Po, and Bla cross-reactive idiotypes. J. Clin. Invest. 87:1603-1613.

5. Harindranath, N., I. S. Goldfarb, H. Ikematsu, S. E. Burastero, R. L. Wilder, A. L. Notkins, and P. Casali. 1991. Complete sequence of the genes encoding the $V_{h}$ and $V_{1}$ regions of low- and high-affinity monoclonal IgM and IgA1 rheumatoid factors produced by CD5+ B cells from a rheumatoid arthritis patient. Int. Immunol. 3:865-875.

6. Ezaki, I., H. Kanda, K. Sakai, N. Fukui, M. Shingu, M. Nobunaga, and T. Watanabe. 1991. Restricted diversity of the variable region nucleotide sequences of the heavy and light chains of a human rheumatoid factor. Arthritis Rheum. 34:343-350.

7. Weisbart, R. H., A. L. Wong, D. Noritake, A. Kacena, G. Chan, C. Ruland, E. Chin, I. S. Y. Chen, and J. D. Rosenblatt. 1991. The rheumatoid factor reactivity of a human IgG monoclonal autoantibody is encoded by a variant $V_{K}$ II L chain gene. J. Immunol. 147:2795-2801.

8. Soto-Gil, R. W., T. Olee, B. K. Klink, T. P. Kenny, D. L. Robbins, D. A. Carson, and P. P. Chen. 1992. A systematic approach to define the germline gene counterparts of a mutated autoantibody from a rheumatoid arthritis patient. Arthritis Rheum. 35:356-363.

9. Olee, T., E. W. Lu, D.-F. Huang, R. W. Soto-Gil, M. Deftos, F. Kozin, D. A. Carson, and P. P. Chen. 1992. Genetic analysis of self-associating IgG rheumatoid factors from two rheumatoid synovia implicates an antigen driven response. J. Exp. Med. 175:831-842.

10. Ermel, R. W., T. P. Kenny, P. P. Chen, and D. L. Robbins. 1993. Molecu- 
lar analysis of rheumatoid factors derived from rheumatoid synovium suggests an antigen-driven response in inflamed joints. Arthritis Rheum. 36:380-388.

11. Randen, I., V. Pascual, K. Victor, K. M. Thompson, O. Forre, J. D. Capra, and J. B. Natvig. 1993. Synovial IgG rheumatoid factors show evidence of an antigen-driven immune response and a shift in the $\mathrm{V}$ gene repertoire compared to IgM rheumatoid factors. Eur. J. Immunol. 23:1220-1225.

12. Lu, E. W., M. Deftos, T. Olee, D.-F. Huang, R. W. Soto-Gil, D. A. Carson, and P. P. Chen. 1993. Generation and molecular analyses of two rheumatoid synovial fluid-derived IgG rheumatoid factors. Arthritis Rheum. 36:927-937.

13. Mantovani, L., R. L. Wilder, and P. Casali. 1993. Human rheumatoid B-la $\left(\mathrm{CD5}^{+} \mathrm{B}\right)$ cells make somatically hypermutated high affinity IgM rheumatoid factors. J. Immunol. 151:473-488.

14. Lautner-Rieske, A., C. Huber, A. Meindl, W. Pargent, K. F. Schable, R. Thiebe, I. Zocher, and H. G. Zachau. 1992. The human immunoglobulin $x$ locus. Characterization of the duplicated A regions. Eur. J. Immunol. 22:1023-1029.

15. Tomlinson, I. M., G. Walter, J. D. Marks, M. B. Llewelyn, and G. Winter. 1992. The repertoire of human germline $V_{H}$ sequences reveals about fifty groups of $\mathrm{V}_{\mathrm{H}}$ segments with different hypervariable loops. J. Mol. Biol. 227:776-798.

16. Matsuda, F., E. K. Shin, H. Nagaoka, R. Matsumura, M. Haino, Y. Fukita, S. Takaishi, T. Imai, J. H. Riley, R. Anand, E. Soeda, and T. Honjo. 1993. Structure and physical map of 64 variable segments in the 3' 0.8 -megabase region of the human immunoglobulin heavy-chain locus. Nature Genet. 3:88-94.

17. Williams, S. C., and G. Winter. 1993. Cloning and sequencing of human

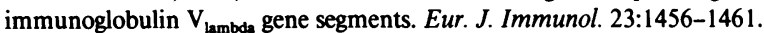

18. Chen, P. P., K. A. Siminovitch, N. J. Olsen, R. A. Erger, and D. A. Carson. 1989. A highly informative probe for two polymorphic Vh gene regions which contain one or more autoantibody-associated Vh genes. J. Clin. Invest. 84:706710 .

19. Yang, P.-M., N. J. Olsen, K. A. Siminovitch, T. Olee, F. Kozin, D. A Carson, and P. P. Chen. 1990. Possible deletion of a developmentally regulated Vh gene in autoimmune disease. Proc. Natl. Acad. Sci. USA. 87:7907-7911.

20. Olee, T., P.-M. Yang, K. A. Siminovitch, N. J. Olsen, J. Hillson, J. Wu, F Kozin, D. A. Carson, and P. P. Chen. 1991. Molecular basis of an autoantibodyassociated restriction fragment length polymorphism that confers susceptibility to autoimmune diseases. J. Clin. Invest. 88:193-203.

21. Schaible, G., G. A. Rappold, W. Pargent, and H. G. Zachau. 1993. The immunoglobulin kappa locus: Polymorphism and haplotypes of Caucasoid and non-Caucasoid individuals. Hum. Genet. 91:261-267.

22. Sasso, E. H., K. W. Van Dijk, A. P. Bull, and E. C. B. Milner. 1993. A fetally expressed immunoglobulin $\mathrm{V}_{\mathrm{H}} 1$ gene belongs to a complex set of alleles. $J$. Clin. Invest. 91:2358-2367.

23. Adderson, E. E., F. H. Azmi, P. M. Wilson, P. G. Shackelford, and W. L. Carroll. 1993. The human VH3b gene subfamily is highly polymorphic. $J$. Immunol. 151:800-809.

24. Shlomchik, M. J., A. Marshak-Rothstein, C. B. Wolfowicz, T. L. Rothstein, and M. G. Weigert. 1987. The role of clonal selection and somatic mutation in autoimmunity. Nature (Lond.). 328:805-811.

25. Tillman, D. M., N.-T. Jou, R. J. Hill, and T. N. Marion. 1992. Both IgM and IgG anti-DNA antibodies are the products of clonally selective B cell stimulation in (NZB $\times$ NZW)F, mice. J. Exp. Med. 176:761-779.

26. Lu, E. W., M. Deftos, H. Tighe, D. A. Carson, and P. P. Chen. 1992 Generation and characterization of two monoclonal self-associating IgG rheumatoid factors from a rheumatoid synovium. Arthritis Rheum. 35:101-105.

27. Ravetch, J. V., U. Siebenlist, S. Korsmeyer, T. Waldmann, and P. Leder. 1981. Structure of the human immunoglobulin mu locus: Characterization of embryonic and rearranged $\mathrm{J}$ and $\mathrm{D}$ genes. Cell. 27:583-591.

28. Hieter, P. A., E. E. Max, J. G. Seidman, Jr. Maizel, J. V., and P. Leder. 1980. Cloned human and mouse kappa immunoglobulin constant and $\mathrm{J}$ region genes conserve homology in functional segments. Cell. 22:197-207.

29. Vasicek, T. J., and P. Leder. 1990. Structure and expression of the human immunoglobulin lambda genes. J. Exp. Med. 172:609-620.

30. Devereux, J., P. Haeberli, and O. Smithies. 1984. A comprehensive set of sequence analysis programs for the VAX. Nucleic Acids Res. 12:387-395.

31. Berman, J. E., S. J. Mellis, R. Pollock, C. L. Smith, H. Suh, B. Heinke, C. Kowal, U. Surti, L. Chess, C. R. Cantor, and F. W. Alt. 1988. Content and organization of the human Ig $\mathrm{V}_{\mathrm{H}}$ locus: definition of three new $\mathrm{V}_{\mathrm{H}}$ families and linkage to the $\operatorname{Ig~C}_{\mathrm{H}}$ locus. EMBO (Eur. Mol. Biol. Organ.) J. 7:727-738.

32. Deftos, M., R. Soto-Gil, M. Quan, T. Olee, and P. P. Chen. 1994. Utilization of a potentially universal downstream primer in the rapid identification and characterization of $\mathrm{V} \lambda$ genes from two new human $\mathrm{V} \lambda$ gene families. Scand. $J$ Immunol. 39:95-103.

33. Siminovitch, K. A., V. Misener, P. C. Kwong, Q-L. Song, and P. P. Chen 1989. A natural autoantibody is encoded by germline heavy and lambda ligh chain variable region genes without somatic mutation. J. Clin. Invest. 84:1675 1678 .

34. Daley, M. D., T. Olee, H. Peng, R. W. Soto-Gil, P. P. Chen, and K Siminovitch. 1992. Molecular characterization of the human immunoglobulin V $\lambda$ I germline gene repertoire. Mol. Immunol. 29:1031-1042.

35. Daley, D. D., H. Peng, V. Misener, X-Y. Liu, P. P. Chen, and K. Siminovitch. 1992. Molecular analysis of human immunoglobulin $\mathrm{V} \lambda$ germline genes:

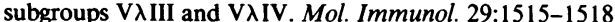

36. Kodaira, M., T. Kinashi, I. Umemura, F. Matsuda, T. Noma, Y. Ono, and
T. Honjo. 1986. Organization and evolution of variable region genes of the human immunoglobulin heavy chain. J. Mol. Biol. 190:529-541.

37. Sanz, I., P. Kelly, C. Williams, S. Scholl, P. Tucker, and J. D. Capra. 1989. The smaller human $V_{H}$ gene families display remarkably little polymorphism. EMBO (Eur. Mol. Biol. Organ.) J. 8:3741-3748.

38. Lee, K. H., F. Matsuda, T. Kinashi, M. Kodaira, and T. Honjo. 1987. A novel family of variable region genes of the human immunoglobulin heavy chain. J. Mol. Biol. 195:761-768.

39. Chen, P. P., and P-M. Yang. 1990. A segment of the human Vh gene locus is duplicated. Scand. J. Immunol. 31:593-599.

40. Chen, P. P. 1990. Structural analyses of human developmentally regulated Vh3 genes. Scand. J. Immunol. 31:257-267.

41. Mortari, F., J. A. Newton, J. Y. Wang, and J. W. Schroeder, Jr. 1992. The human cord blood antibody repertoire. Frequent usage of the $\mathrm{V}_{\mathrm{H}} 7$ gene family. Eur. J. Immunol. 22:241-245.

42. Kuppers, R., U. Fischer, K. Rajewsky, and A. Gause. 1992. Immunoglobulin heavy and light chain gene sequences of a human CD5 positive immunocytoma and sequences of four novel $\mathrm{V}_{\mathbf{H}}$ III germline genes. Immunol. Lett. 34:5762.

43. Pech, M., and H. G. Zachau. 1984. Immunoglobulin genes of different subgroups are interdigitated within the Vk locus. Nucleic Acids Res. 12:92299236.

44. Pargent, W., K. F. Schable, and H. G. Zachau. 1991. Polymorphisms and haplotypes in the human immunoglobulin $x$ locus. Eur. J. Immunol. 21:18291835.

45. Shefner, R., G. Kleiner, A. Turken, L. Papazian, and B. Diamond. 1991 A novel class of anti-DNA antibodies identified in BALB/c mice. J. Exp. Med. 173:287-296.

46. Schroeder H. W., Jr., J. L. Hillson, and R. M. Perlmutter. 1987. Early restriction of the human antibody repertoire. Science (Wash. DC) .238:791-793.

47. Schutte, M. E. M., S. B. Ebeling, K. E. Akkermans, F. H. J. Gmelig-Meyling, and $T$. Logtenberg. 1991. Antibody specificity and immunoglobulin $\mathrm{V}_{\mathrm{H}}$ gene utilization of human monoclonal $\mathrm{CD}^{+} \mathrm{B}$ cell lines. Eur. J. Immunol 21:1115-1121

48. Weng, N.-P., L.-Y. Yu-Lee, I. Sanz, B. M. Patten, and D. M. Marcus 1992. Structure and specificities of anti-ganglioside autoantibodies associated with motor neuropathies. J. Immunol. 149:2518-2529.

49. Hughes-Jones, N. C., J. M. Bye, D. Beale, and J. Coadwell. 1990. Nucleotide sequences and three-dimensional modelling of the $V_{H}$ and $V_{L}$ domains of two human monoclonal antibodies specific for the $\mathrm{D}$ antigen of the human $\mathrm{Rh}$-bloodgroup system. Biochem. J. 268:135-140.

50. Thomas, J. W. 1993. V region diversity in human anti-insulin antibodies: Preferential use of a $\mathrm{V}_{\mathrm{H}}$ III gene subset. J. Immunol. 150:1375-1382.

51. Siminovitch, K. A., V. Misener, P. C. Kwong, P.-M. Yang, C. A. Laskin, E. Cairns, D. Bell, L. A. Rubin, and P. P. Chen. 1990. A human anti-cardiolipin autoantibody is encoded by developmentally restricted heavy and light chain variable region genes. Autoimmunity. 8:97-105.

52. Hillson, J. L., and R. M. Perlmutter. 1990. Autoantibodies and the fetal antibody repertoire. Int. Rev. Immunol. 5:215-230.

53. Bentley, D. L. 1984. Most $k$ immunoglobulin mRNA in human lymphocytes is homologous to a small family of germ-line V genes. Nature (Lond.). 307:77-80

54. Settmacher, U., S. Jahn, P. Siegel, R. Von Baehr, and A. Hansen. 1993 An anti-lipid A antibody obtained from the human fetal repertoire is encoded by $\mathrm{V}_{\mathrm{H}} 6-\mathrm{V}_{\text {lambda }} 1$ genes. Mol. Immunol. 30:953-954.

55. Wu, T. T., and E. A. Kabat. 1982. Fourteen nucleotides in the second complementarity-determining region of a human heavy-chain variable region gene are identical with a sequence in a human $D$ minigene. Proc. Natl. Acad. Sci. USA. 79:5031-5032.

56. Takahashi, N., T. Noma, and T. Honjo. 1984. Rearranged immunoglobulin heavy chain variable region ( $\mathrm{Vh}$ ) pseudogene that deletes the second complementarity-determining region. Proc. Natl. Acad. Sci. USA. 81:5194-5198.

57. Siebenlist, U., J. V. Ravetch, S. Korsmeyer, T. Waldmann, and P. Leder. 1981. Human immunoglobulin D segments encoded in tandem multigenic families. Nature (Lond.). 294:631-635.

58. Reynaud, C.-A., V. Anquez, H. Grimal, and J.-C. Weill. 1987. A hyperconversion mechanism generates the chicken light chain preimmune repertoire. Cell. 48:379-388.

59. Carlson, L. M., W. T. McCormack, C. E. Postema, E. H. Humphries, and C. B. Thompson. 1990. Templated insertions in the rearranged chicken IgL V gene segments arise by intrachomosomal gene conversion. Genes \& Dev. 4:536547.

60. Larrick, J. W., L. Danielsson, C. A. Brenner, M. Abrahamson, K. E. Fry, and C. A. K. Borrebaeck. 1989. Rapid cloning of rearranged immunoglobulin genes from human hybridoma cells using mixed primers and the polymerase chain reaction. Biochem. Biophys. Res. Commun. 160:1250-1256.

61. Dorai, H., J. E. Bubbers, and S. D. Gillies. 1992. Cloning and reexpression of a functional human IgM anti-lipid A antibody. Hybridoma. 11:667-675.

62. Zebedee, S. L., C. F. III Barbas, Y.-L. Hom, R. H. Caothien, R. Graff, J. DeGraw, J. Pyati, R. LaPolla, D. R. Burton, R. A. Lerner, and G. B. Thornton 1992. Human combinatorial antibody libraries to hepatitis B surface antigen. Proc. Natl. Acad. Sci. USA. 89:3175-3179. 